\title{
IDENTIDADE, TRABALHO E APOSENTADORIA: ESTUDO COM TRABALHADORAS APOSENTADAS DE UMA FUNDAÇÃO PÚBLICA
}

\author{
Magda Maria Augusto', Ivan Rocha Neto²
}

1 Doutoranda do programa Educação em Ciências: Química da Vida e Saúde da Universidade Federal do Rio Grande do Sul, UFRGS (magda.augusto@gmail.com).

2 Professor Doutor do programa Educação em Ciências: Química da Vida e Saúde da Universidade Federal do Rio Grande do Sul, UFRGS, Porto Alegre,RS,Brasil.

Recebido em: 08/04/2016 - Aprovado em: 30/05/2016 - Publicado em: 20/06/2016 DOI: 10.18677/Enciclopedia_Biosfera_2016_141

\section{RESUMO}

Este estudo busca uma discussão sobre como o trabalho influencia a construção da identidade e quais suas consequências frente à aposentadoria. Os sujeitos desta pesquisa consistiram em servidoras aposentadas de uma agência pública de fomento à ciência e Tecnologia, localizada no Distrito Federal. Especificamente, buscou-se caracterizar o contexto de vida atual nas dimensões das relações sociais, das atividades ora desenvolvidas e suporte familiar; descrever as vivências de prazer e sofrimento e investigar os mecanismos utilizados para mediar o sofrimento. Foram realizadas duas entrevistas semiestruturadas coletivas que foram analisadas por meio da Análise de Núcleo de Sentido. Os resultados, com base nos depoimentos colhidos nas entrevistas, evidenciam o quanto o trabalho implica diretamente nas diversas formas de inserção social dos sujeitos e mostra a dificuldade e o sofrimento que emergem da perda da identidade social com a ausência do trabalho. Conclui-se que o sofrimento advindo da aposentadoria está fortemente relacionado à ausência de um projeto de preparação para a aposentadoria.

PALAVRAS-CHAVE: prazer, políticas públicas, sofrimento.

\section{IDENTITY, WORK AND RETIREMENT: STUDY OF RETIRED EMPLOYEES OF A PUBLIC FOUNDATION}

\begin{abstract}
This study aims a discussion about how work influences the construction of identity and what its consequences forward to retirement. The subjects are servants retired from a public agency promoting science and technology, located in the Federal District. Specifically, it sought to characterize the context of current life in the dimensions of social relations, now developed activities and family support; describes the experiences of pleasure and pain and investigates the mechanisms used to mediate suffering. Two collective semi-structured interviews were conducted that were analyzed by the ANS. The results, based on interviews conducted; show how much work involves directly the various forms of social integration of subjects and shows the difficulty and suffering that emerge from the loss of social identity with
\end{abstract}


absence of work. We conclude that the suffering arising from the retirement is strongly related to the absence of a preparing project for retirement.

KEYWORDS: pain, pleasure, public policy.

\section{INTRODUÇÃO}

O aumento da expectativa de vida no Brasil tem como consequência o crescimento do número de pessoas aposentadas (ANTES et al., 2014; RIBEIRO et al., 2015). Essa questão vem chamando a atenção tanto de núcleos de pesquisa quanto do Estado, entrando na pauta das prioridades governamentais e geração de políticas públicas urgentes para se lidar com tal situação (RAFALSKI \& DE ANDRADE, 2016).

A possibilidade de aposentar-se surgiu na Alemanha, no final do século XIX, mais precisamente em 1889, no governo do chanceler Otto von Bismarck - não por entendimento de que seria um legítimo direito do trabalhador após anos e anos de venda de sua força de trabalho, mas sim, numa tentativa de impedir o crescimento das ideias socialistas que então viralizavam pela Europa. Trabalhadores do comércio, da agricultura ou da incipiente indústria, quando completavam 70 anos, adquiriam o direito ao benefício da aposentadoria. Essa estratégia alemã logo foi estendida como uma onda pelo restante da Europa, começando pela Hungria e Áustria (IBRAHIM, 2010).

Em 1923, seguindo a tendência mundial, surgiu no Brasil a primeira lei que tratou da aposentadoria, porém, destinada apenas aos ferroviários. Contudo, outras leis foram sendo editadas ao longo do tempo para beneficiar as demais categorias. Para analisar as múltiplas facetas e abordagens associadas à aposentadoria, é fundamental entender a relação do trabalhador com o trabalho. Atualmente, o trabalho reveste-se de uma importância tamanha na vida do sujeito histórico e da sociedade envolvente. Desta forma, os profissionais da Psicodinâmica do Trabalho passaram a integrar a corrente que caracteriza o fenômeno não como mera atividade, mas como elemento fundador tanto do homem, em sua humanidade, quanto da sociedade como forma de o homem organizar-se para o domínio da natureza e a proteção contra essa natureza e os demais homens.

HELOANI \& LANCMAN (2004) relatam que o trabalho assume um papel central na constituição da identidade individual e possui implicação direta nas diversas formas de inserção social dos indivíduos. Nesse sentido, o trabalho pode ser visto como fundamental na constituição de redes de relações sociais e de trocas afetivas e econômicas, base da vida cotidiana das pessoas.

De acordo com LANCMAN \& GHIRARDI (2002), muitos autores discutem a centralidade do trabalho no mundo social, sua importância nas relações indivíduosociedade e na constituição do próprio indivíduo. O trabalho representa muito mais que $o$ ato de trabalhar ou de vender sua força de trabalho em busca de remuneração. Há também uma remuneração social pelo trabalho, ou seja, o trabalho enquanto fator de pertinência a grupos e a certos direitos sociais.

O trabalho possui, ainda, uma função psíquica, enquanto um dos grandes alicerces da constituição do sujeito e da sua rede de significados (BITENCOURT et al., 2011). Processos como reconhecimento, gratificação, mobilização da inteligência, além de estarem relacionados à realização do trabalho, estão ligados à constituição da identidade e da subjetividade. 


\section{A Psicodinâmica do Trabalho}

Até o final do século XX, tão só os efeitos deletérios da organização, capazes de comprometer a saúde dos trabalhadores, eram observados pela Psicopatologia do Trabalho. Com o advento da Psicodinâmica do Trabalho, a superação do sofrimento levou o trabalhador não apenas a vencer pelo trabalho aspectos que surgem, como o sofrimento, mas ainda a se tornar sujeito histórico e a participar da construção do mundo social (DEJOURS, 2008a).

A discussão acerca dos distúrbios psicossomáticos - com ênfase para o que os psiquiatras então chamavam de "a loucura" -, sobretudo em relação àqueles originários do trabalho, ocorreu na França, logo após a Segunda Guerra Mundial. Os programas classificados como de esquerda exerciam grande influência tanto nos sindicatos de trabalhadores como também nos meios intelectuais comprometidos com as pesquisas sociais.

Sobre as condições de saúde psíquica de homens e mulheres envolvidos com uma atividade profissional, os pesquisadores então propunham observar como as condições de trabalho interfeririam em possíveis disfunções psíquicas, podendo mesmo acarretar disfunções somáticas. Desta forma, o trabalho aparecia sob duas perspectivas: primeiro, como forma de exploração dos capitalistas sobre os desvalidos. Uma ótica histórica então corrente do trabalhador observado como sujeito social produtor de mais-valia, com um papel histórico ainda latente. A segunda perspectiva está relacionada à ascensão meritocrática rumo ao sucesso pessoal em um propagado American way of life, ou em um Estado de bem-estar social, como preferiam os programas sociais democratas presentes em importantes países europeus; um contraponto, seja em relação ao liberalismo norte-americano, seja em relação ao socialismo soviético.

A construção teórica da Psicopatologia do Trabalho só foi possível a partir do estudo no campo da "anormalidade", em outros termos, sobre os efeitos patogênicos que o trabalho e sua organização causam ao trabalhador. É a razão de se tratar de uma análise reservada, sobretudo a pesquisadores da área da saúde.

Em 1980, Dejours, com sua proposta de seminário entre os pares para a discussão da epistemologia de uma nova ciência a um só tempo social, da saúde e do comportamento, e sua posterior publicação como Addendum (DEJOURS, 2008 a), amplia a dimensão do estudo sobre as possíveis repercussões do trabalho na psique, ao definir o conceito de "sofrimento no trabalho" como característica própria a homens e mulheres, não revestindo qualquer aspecto de anormalidade ou característica estritamente patogênica.

Desta forma, o psiquiatra francês Dejours inaugurou um novo momento, não simplesmente uma ruptura entre a Psicodinâmica do Trabalho e da Ação e a Psicopatologia do Trabalho, até então praticada e voltada exclusivamente para os aspectos patogênicos presentes em muitas das disfunções causadas, mas sobretudo pela cultura organizacional do trabalho em um momento de grande crescimento econômico, como foi característico no momento de reconstrução de boa parte do mundo destruído na Segunda Guerra Mundial (DEJOURS, 2008 a). A Psicodinâmica do Trabalho e da Ação é mais um alargamento do campo de análise, ou seja uma proposta que assimila a experiência já consolidada da Psicopatologia do Trabalho para seguir adiante com uma nova proposta.

DEJOURS (2008 a) advoga que a Psicodinâmica não tem por objetivo apenas pôr um termo ao sofrimento, e sim transformá-lo, vislumbrando mesmo a possibilidade de se encontrar prazer no trabalho, vencido o sofrimento. Deve se 
destacar ainda o fato de a identidade do sujeito histórico - aquele que é capaz de sair em busca da ação arendtiana - também se definir por conta do papel que desempenha socialmente por meio do exercício de seu ofício, forma contemporânea de trabalhadores e trabalhadoras conquistarem o seu espaço social e contribuírem para essa construção do mundo, com a consciência do alcance de seu ato.

As mudanças percebidas ao se comparar a tradicional concepção da Psicopatologia do Trabalho e a nova perspectiva aberta com a proposta da Psicodinâmica do Trabalho e da Ação são inevitáveis. O objeto de estudo dos pesquisadores de laboratórios de Psicodinâmica do Trabalho, como já se mencionou, deixa de ser a "anormalidade" e o "patológico" de forma estrita e passa a ser a "normalidade" e a "saúde".

É facilmente demonstrável que o envolvimento com o trabalho, não se reduz a uma mera sequência no tempo, é toda a subjetividade que é arrebatada nesse movimento, até o mais íntimo do ser. E essa é justamente uma das razões pelas quais é possível o adoecimento em decorrência do trabalho, ou, no sentido oposto, o trabalhar ser transformado em júbilo e realização pessoal, estar na base mesma da identidade do trabalhador (DEJOURS, 2007). O sofrimento diretamente vinculado à organização do trabalho e sua necessária superação são apresentados da seguinte forma:

"O trabalho implica sempre um confronto com o real. Um real que se deixa conhecer por sua resistência a se submeter aos conhecimentos e às diferentes formas de saber-fazer. Este confronto é gerador de sofrimento, um sofrimento que se torna patogênico - comprometendo a saúde - quando o confronto se torna intransponível e leva à repetição constante dos mesmos problemas, dos mesmos fracassos, tornando-se insuportável" (DEJOURS, 2008 b).

A partir desse entendimento, a palavra "trabalho" toma um lugar central do processo de intersubjetividade das relações no trabalho nessa transformação do sofrimento pelo reconhecimento. O trabalho passou a ser também trabalho da palavra, o "mundo muscular" transformado em "mundo verbal", os "comportamentos pragmáticos" passaram a ser "comportamentos compreensivos", segundo RICOEUR (2010) citado por KARAM (2010).

A metamorfose desse sofrimento transforma-se em reconhecimento e prazer, mediante o emprego da palavra. Segundo a acepção de Ricoeur, significa que "falar o seu trabalho é aceder à palavra de homem político" (RICOEUR, 2010 citado por KARAM, 2010), uma vez mais a práxis arendtiana integra o quadro da centralidade do trabalho no sentido de posicionar o homem como sujeito histórico, no sentido de protagonizar a transformação não apenas da organização do trabalho, mas de ser ator na construção do mundo no qual se situa mediante o seu trabalho, que o filósofo francês denomina como confluência da "civilização do trabalho e civilização da palavra".

A política, como se pode observar, não está ausente, pelo contrário. Contudo, deixa de ser um cardápio pronto para transformar-se em construção permanente do "Eu" no trabalhar em um mundo concreto, onde o esforço é recompensado pelo reconhecimento. Não é outra a razão de DEJOURS (2008 a) insistir na denominação de trabalho vivo, um contraponto indispensável à cultura organizacional, esta absolutamente dependente da força presente no trabalho vivo. Não é outra a razão de a grande obra sobre o trabalho de Dejours ter por título travail vivant (trabalho vivo), ainda sem tradução no Brasil. 
Diante do exposto acima, buscou-se analisar as vivências de prazer e sofrimento daqueles que não mais têm a sua subjetividade atrelada à organização do trabalho. Objetivou-se investigar as vivências de prazer e sofrimento advindas pela aposentadoria por servidoras de uma fundação pública.

\section{MATERIAL E MÉTODOS}

O estudo foi conduzido a partir da análise das vivências de prazer/sofrimento no cotidiano de mulheres aposentadas de uma fundação pública. A participação foi voluntária de trabalhadoras aposentadas e perfez uma amostra de cinco servidoras. As funcionárias participantes foram todas do sexo feminino, com faixa etária entre 54 e 58 anos. Todas as participantes têm nível superior completo, sendo duas com doutorado, duas com mestrado e uma com especialização.

O molde de pesquisa usado foi qualitativo. Este tipo de pesquisa é considerado uma forma eficaz para a produção e construção de modelos teóricos de inteligibilidade no estudo de sistemas que não são diretamente acessíveis. A teoria é definida pelo autor como "a construção de um sistema de representações capaz de articular diferentes categorias entre si” (GONZÁLEZ REY, 2005).

DEJOURS (2004) autentica a Psicodinâmica do Trabalho como uma disciplina que recorre à técnica da interpretação; portanto, esta se enquadra na epistemologia das ciências históricas-hermenêuticas. Porém, se ajusta também ao grupo das ciências críticas, pois tem fundamentalmente como objetivo um trabalho de reapropriação e de emancipação na crítica das distorções do agir comunicacional.

Nos textos de Psicodinâmica do Trabalho fica reforçada a ideia de que o acesso à vivência do sujeito só pode existir se mediatizada pela palavra. A praxis ligada à inteligência da prática, a ação deliberada e refletida - não pode ser entendida sem que o sujeito fale sobre ela, elabore o seu próprio discurso sobre ela. Dessa forma, a metodologia em Psicodinâmica do Trabalho é baseada na fala do sujeito, do sujeito em situação de grupo, quando é possível expressar sua vivência e elaborar, de maneira compartilhada, uma reflexão sobre a relação entre sofrimento e prazer no cotidiano da aposentadoria.

As entrevistas foram feitas com trabalhadoras organizadas em coletivo, criando um espaço público de discussão em consonância com os princípios da Psicodinâmica do Trabalho. Somente a partir da reflexão que o sujeito é capaz de se reapropriar da realidade relacionada a temática investigada, ou seja, de sua aposentadoria.

As entrevistas semiestruturadas coletivas com o grupo de cinco servidoras foram conduzidas em duas etapas. No primeiro momento objetivou-se a construção de um ambiente adequado para o exercício da palavra e da escuta. Nesse momento, o contrato foi discutido a partir da seguinte pauta: 1. explicitação do projeto de pesquisa (objetivos, metodologia e resultados esperados); 2. Apresentação do termo de compromisso livre e esclarecido.

No segundo momento, buscou-se a reflexão e verbalização das vivências de prazer-sofrimento frente à aposentadoria, bem como das relações sociais atuais, as defesas individuais e/ou coletivas quanto ao sofrimento. As participantes foram recrutadas por meio de um convite encaminhado pelo serviço de e-mail institucional, pois essa instituição preserva aos seus aposentados o acesso ao serviço de email. Cinco, do total de sete servidoras contatadas aceitaram prontamente a participação.

Nesse primeiro encontro, os pesquisadores justificaram a metodologia e a relevância da entrevista coletiva para a construção de um coletivo de trabalho. Após 
a explicitação do projeto de pesquisa (o título, os objetivos, a metodologia), as participantes foram convidadas para as entrevistas. Foram realizadas duas entrevistas coletivas com as cinco servidoras. Cada entrevista, que foi gravada e transcrita integralmente, foi conduzida a partir de quatro eixos temáticos:

1) Contexto atual de vida, a saber: atividades desenvolvidas, relações sociais, percepção quanto ao envelhecimento e suporte familiar;

2) prazer e sofrimento provenientes do não-trabalho;

3) as formas de enfrentamento do sofrimento no não-trabalho;

4) os possíveis impactos sobre a saúde.

Os resultados foram avaliados a partir da técnica de Análise do Núcleo de Sentido (ANS), apresentada por MENDES (2007), que se referenciou na análise de conteúdo categorial de BARDIN (1988), priorizando os aspectos reais e simbólicos da realidade atual das trabalhadoras.

A ANS organiza os dados não só pela recorrência dos temas e dos conteúdos manifestos, mas também pelos conteúdos latentes, contraditórios e essenciais para o objeto em estudo (MENDES, 2007). A unidade de análise para construção dos núcleos de sentidos constitui-se de temas sobressalentes do conteúdo do discurso que foram agrupados em núcleos de sentidos de acordo com semelhanças semânticas. Com a organização dos núcleos, a ação seguinte consistiu na definição de cada núcleo com base nas falas dos sujeitos participantes da pesquisa.

Para este estudo, os núcleos de sentidos não foram definidos a priori. Buscou-se organizar as informações a partir da dinâmica das entrevistadas. Cada núcleo recebeu como denominação uma frase das entrevistadas. Nesse sentido, considerando a organização dos dados, o estudo estruturou os seguintes núcleos:

a) "(...) Continuo a trabalhar, só que com uma rotina diferenciada daquela que tinha na CAPES. Trata-se de uma pequena empresa privada familiar";

b) "(...) Nem sei mais o que quero da vida. Só sei que não quero envelhecer”;

c) "(...) Minha família segurou a onda";

d) "(...)Estou feliz, sem cobranças, sem estresse, sem aborrecimentos...";

e) "(...) Entrei em depressão, tive que ir para terapia.";

f) "(...)Procuro atividades onde me sinto útil, produtiva.

\section{RESULTADOS E DISCUSSÃO}

"(...) Continuo a trabalhar, só que com uma rotina diferenciada daquela que tinha antes......."

Dos sujeitos pesquisados, três continuam atreladas ao trabalho com diferentes vínculos: uma integra, hoje, a equipe de uma empresa familiar; outra permanece na mesma instituição em que se aposentou, porém agora, ocupando um cargo comissionado e a terceira em trabalho voluntário. São também três, as maneiras como encaram suas ocupações.

A trabalhadora que hoje integra uma empresa familiar relata que trabalha numa área administrativa em detrimento da área técnica que ocupava anteriormente. Porém, agora, se sente livre da burocracia que a acompanhou por longos anos. 
Ainda reconhece a vantagem de usufruir de horários flexíveis e enaltece a proximidade das relações sociais.

A segunda servidora, que permanece ocupando um cargo na mesma instituição na qual se aposentou, observa que, apesar de continuar trabalhando em excesso, sente-se mais livre por ter a possibilidade de escolher entre ficar ou sair, ou seja, pode sair a qualquer momento, uma vez que já está aposentada. Quando o trabalho se tornar exaustivo a ponto de impactar na sua qualidade de vida, pode se demitir sem maiores problemas.

A terceira servidora se ocupa, hoje, de um trabalho voluntário e constatou que agora trabalha com "todo o prazer do mundo". Faz aquilo que ama e nem sente o tempo passar, que gostaria de ter mais tempo para dedicar ainda mais àquilo que gosta.

As trabalhadoras comparam suas situações atuais de contexto de trabalho com outrora e concluem que se sentem mais tranquilas com a nova situação. A flexibilização de horário, que lhes permite uma maior autonomia sobre a organização do tempo é comemorada de forma unânime. Ainda ressaltam a ausência de processos burocratizados que contribuem para a insatisfação no trabalho.

Quanto às trabalhadoras que efetivamente se aposentaram, ou seja, àquelas que não estão mais submetidas a uma organização do trabalho, tem-se duas situações distintas, a saber: de um lado, concluem que a aposentadoria significa liberdade e tempo para realizar sonhos de uma vida. Resgataram projetos adiados por anos e avaliam a aposentadoria como uma recompensa pelo tempo dedicado ao trabalho. Por outro lado, relatam sentimentos de perda de referencial identitário "(...) cadê meu crachá, cadê minha identidade?" trazem dificuldades em reorganizar suas rotinas uma vez que o trabalho sempre significou o centro de suas vidas. Essas trabalhadoras expressam que suas rotinas sempre foram determinadas em função do trabalho. Segundo elas a vida girava em torno do trabalho e seus compromissos eram definidos a partir das "brechas" que o trabalho permitia. Assim, sentem-se sem referência, inclusive de tempo, na organização de suas atividades.

“(...) Nem sei mais o que quero da vida. Só sei que não quero envelhecer."

As trabalhadoras associam muito fortemente a aposentadoria com a noção do próprio envelhecimento. Perdem um pouco do sentido da vida com o distanciamento do trabalho, como se o sentido de suas existências fosse unicamente ligado ao trabalho. Relatam que o termo aposentadoria simboliza para elas o início do processo de decadência física e mental, o instante que antecede as doenças e a morte.

Questionadas pelos pares da pesquisa se sempre tiveram esta percepção da aposentadoria, responderam que não saberiam responder ou que nunca haviam parado para pensar sobre o pós-carreira, que sentiam como uma possibilidade distante até perceberem-se nesta situação.

“(...) Minha família segurou a onda”.

A importância do suporte familiar ficou evidenciada na fala das trabalhadoras. “(...) Graças a Deus tive o apoio da minha família." Quando apareciam os primeiros sintomas de adoecimento ou sofrimento psíquico em decorrência do baixo nível de 
adaptação das servidoras à aposentadoria, estes eram detectados primeiramente pela família. "(...) meu marido praticamente me obrigou a procurar ajuda na terapia". "(...) Estou feliz, sem cobranças, sem stress, sem aborrecimentos".

$\mathrm{Na}$ condição de aposentadas estas declaram um estado de total bem-estar. Associam fortemente, agora, aposentadoria com liberdade. Dizem que não se lembravam mais como é viver sem estresse. "(...) no momento em que os filhos estão já criados e cuidando de suas próprias vidas, que tenho um salário todo mês depositado e nenhuma cobrança pelo meu desempenho, posso dizer: sou livre." Relatam ser muito bom trabalhar com aquilo que se identifica, ou antes, trabalhar se e quando quiser.

\section{"(...) Entrei em depressão, tive que ir para terapia."}

Quando arguidas sobre o aparecimento de alguma espécie de sofrimento, responderam algumas, que passaram por uma fase de sofrimento. Porém por unanimidade concluíram que haviam superado essa fase. Entretanto essas vivências não foram sentidas com a mesma intensidade ou, pelo menos, com a mesma duração. Aquelas que apresentaram um suporte familiar mais eficaz conduzindo-as para médicos e psicólogos - superaram com maior rapidez em detrimento daquelas que contavam com o apoio familiar no sentido de unicamente entender e compartilhar de suas angústias.

\section{“(...) Procuro atividades onde me sinto útil, produtiva...}

Como mecanismo de enfrentamento do sofrimento, essas mulheres aposentadas procuraram o caminho de resgate de suas identidades sociais exercendo atividades onde se sentiram úteis, produtivas. Parece que sentem necessidade de responder a uma cobrança social; em especial, por viverem em uma sociedade capitalista em que seu valor é medido pela sua utilidade ao sistema. Assim, o reconhecimento social é adquirido por meio de um trabalho, mesmo que não remunerado.

A presente pesquisa procurou analisar as vivências de sofrimento de trabalhadoras em relação à aposentadoria. Tentou, ainda, suprir uma lacuna identificada na abordagem da Psicodinâmica do Trabalho sobre o tema aposentadoria, uma vez que não foi possível encontrar matéria específica sobre o sofrimento advindo da ausência do trabalho sobre os aposentados nesta teoria. A grande maioria dos trabalhos analisados tratava da aposentadoria relacionada ao envelhecimento (MENDES et al., 2005; DE SOUZA et al., 2014). Há uma escassez de pesquisas sobre aposentadoria que tivessem como aporte teórico a Psicodinâmica do Trabalho (MARTINS et al., 2014).

Assim, a pesquisa foi realizada à luz da Psicodinâmica do Trabalho e dos relatos coletivos dos trabalhadores. Nos resultados, destacou-se a ausência de espaços para visibilidade da contribuição dos sujeitos à sociedade na ausência do trabalho, afetando a dinâmica do reconhecimento social. O julgamento da qualidade do trabalho realizado (retribuição simbólica que poderia conferir aos sujeitos um sentimento de pertencimento, uma possibilidade de construção de sua identidade) é, assim, impedido. 
DEJOURS (2011) propõe "atividade coordenada útil" como definição de trabalho, ou seja, uma ocupação com um propósito, que envolva um coletivo e que tenha valor técnico, social ou econômico. Isso não se aplica ao lazer (falta-lhe o critério de utilidade), mas aplica-se a várias atividades associativas, políticas, artísticas e educativas. Portanto, pode-se concluir que, ao aposentar-se de um trabalho formal, existem várias formas de obter-se a gratificação que aquele proporcionava.

Como colocam SOARES \& COSTA (2011), a identidade psicológica e social se forma na relação com os outros. Assim, o trabalho possibilita identificações e ampliação das perspectivas de significados. Os sujeitos são capazes de estabelecerem representações de si de acordo com o cenário profissional, bem como, das relações pessoais ali estabelecidas.

Por outro lado, percebem-se polaridades presentes ao trabalhar e se aposentar. O sentimento de liberdade, bem como o sentimento de crise identiária, surgem nesta etapa. Segundo DEJOURS et al. (1994), o trabalho, ao mesmo tempo em que é fonte de satisfação e realização, também é fonte de sobrevivência e sofrimento.

Para SANTOS (1990), há duas formas, geralmente concomitantes, de lidar com a aposentadoria: crise - pela recusa em aceitar a condição de aposentado, especialmente devido à imagem estigmatizada vinculada à inatividade que tal condição confere; liberdade - sentimento resultante da busca pelo prazer em atividades de lazer e concretização de planos anteriormente não possíveis de se realizarem pelo compromisso/obrigação de trabalhar.

Apesar de serem obrigatórios, a partir da criação da Política Nacional do Idoso, os programas de Preparação para a Aposentadoria (PPA) ainda são incipientes nas organizações brasileiras. Na organização estudada, houve uma tentativa de implantação do PPA no ano de 2013, o qual se limitou a uma oferta de oficina de sensibilização para o programa; ou seja, não avançou para uma efetiva implementação do programa.

Na obra Psychopathologie du travail, (DEJOURS \& GERNET, 2012), há uma lista de psicopatologias associadas ao trabalho - patologias da sobrecarga, do estresse pós-traumático, do assédio moral, do suicídio e tentativas, vícios e drogadição e - sendo a investigação relacionada a patologia do desemprego. Esta última está muito ligada à questão da perda (do emprego, do salário, da atividade e do status, dos laços sociais, do sentimento de utilidade...). Segundo DEJOURS \& GERNET (2012), os indivíduos desse quadro podem enfrentar problemas de humor (como a depressão) ou de comportamento (raiva, agressividade).

As maiores repercussões do desemprego na saúde mental são em termos de autoestima, do suporte social, da identidade e das relações. Esse quadro vai se agravando com o passar do tempo e desestabiliza a economia psíquica, marginalizando o indivíduo da sociedade. Essa situação pode inclusive atrapalhar o desenvolvimento e o engajamento em outras.

Trabalhar não é somente produzir; é transformar a si mesmo e, no melhor dos casos, é uma ocasião oferecida à subjetividade para se testar, até mesmo para se realizar (DEJOURS, 2004). Não trabalhar priva o sujeito de um espaço de autoexpressão, o que também pode ser danoso à saúde. O ideal não é o estado de inatividade ou desemprego, a questão não é escolher entre trabalhar e não trabalhar, mas qual trabalho exercer (DEJOURS, 1986, 1987, 2011). 


\section{CONCLUSÕES}

A partir das conclusões deste estudo, sugere-se a criação, na instituição estudada, de um programa voltado para a orientação psicológica para a aposentadoria, que ofereça aos trabalhadores um acompanhamento psicológico durante seu percurso profissional.

Uma implantação de programa de educação para a aposentadoria faz-se necessária e urgente, de forma a possibilitar ao sujeito, ainda na fase de préaposentadoria, a elaboração de um novo projeto de vida.

Com os resultados desta pesquisa, busca-se contribuir para a criação e implementação de políticas de gestão de pessoas orientadas para as questões que envolvem a aposentadoria dos servidores na instituição estudada.

Como uma forma de superar as limitações desta pesquisa, sugere-se, para trabalhos futuros, um aprofundamento no estudo da aposentadoria pela teoria da Psicodinâmica do Trabalho; pois o sofrimento psíquico do trabalhador devido à aposentadoria reflete tanto na sua própria saúde como se prolonga ao Estado, que arcará com maiores despesas com saúde, decorrentes do sofrimento psíquico que acomete os sujeitos despreparados para esta nova etapa da vida.

Espera-se, por fim, que esta pesquisa possibilite reflexões acerca da aposentadoria no serviço público bem como a produção do conhecimento sobre prazer e sofrimento decorrente da ausência de trabalho.

\section{REFERÊNCIAS}

ANTES, D. L.; RIBEIRO, D. F.; SCHNEIDER, I. J. C.; BENEDETTI, T. R. B.; D'ORSI, E. Perfil socioeconômico dos idosos de Florianópolis: Análise comparativa dos estudos Perfil do Idoso 2002 e EpiFloripa Idoso 2009. Revista Brasileira de Epidemiologia, v. 17, n. 1, p. 189-202, 2014.

BARDIN, L. Análise de conteúdo. Lisboa: Edições 70, 1988.

BITENCOURT, B. M.; BATISTA, M. K.; PICCINI, V. C. Para além do tempo de emprego: o sentido do trabalho no processo de aposentadoria. Revista de Ciências da Administração, v. 13, n. 31, p. 30-57, 2011. Disponível em: < http://dx.doi.org/10.5007/2175-8077.2011v13n31p30>. doi: 10.5007/21758077.2011v13n31p30.

DEJOURS, C. Por um novo conceito de saúde. Revista Brasileira de Saúde Ocupacional, v. 4, n. 54, p. 7-11, 1986.

DEJOURS, C. A loucura do trabalho. São Paulo: Oboré, 1987.

DEJOURS, C. Da Psicopatologia à Psicodinâmica do Trabalho. Rio de Janeiro: Fiocruz, Brasília: Paralelo 15, 2004.

DEJOURS, C. La psychodynamique du travail face à l'évaluation: de la critique à la proposition. Travailler, v. 1, n. 25, p. 15-27, 2011. 
DEJOURS, C. A Psicodinâmica do Trabalho na pós-modernidade. In: MENDES, A. M.; CRUZ, S. C.; FACAS, E. P. (Orgs.). Diálogos em Psicodinâmica do Trabalho. Brasília: Paralelo 15, 2007.

DEJOURS, C. Addendum: da psicopatologia à Psicodinâmica do Trabalho. In: LANCMAN, S.; SZNELWAR, L. I. (Orgs.). Christophe Dejours: da psicopatologia à Psicodinâmica do Trabalho. Brasília/Rio de Janeiro: Paralelo 15/ Editora Fiocruz, 2008 a.

DEJOURS, C.; GERNET, I. Psychopathologie du travail. Paris: Elsevier Masson, 2012.

DEJOURS, C.; JAYET, C.; ABDOUCHELI, E. Psicodinâmica do trabalho: contribuições da Escola Dejouriana à análise da relação prazer, sofrimento e trabalho. São Paulo: Atlas, 1994.

DEJOURS, C.; MOLINIER, P. O trabalho como enigma. In: LANCMAN, S.; SZNELWAR, L. I. (Orgs.). Christophe Dejours: da psicopatologia à Psicodinâmica do Trabalho. Brasília/Rio de Janeiro: Paralelo 15/ Editora Fiocruz, 2008 b.

DE SOUZA, A. C. S. N.; LODOVICI, F. M. M.; SILVEIRA, N. D. R.; ARANTES, R. P. G. Alguns apontamentos sobre o Idadismo: a posição de pessoas idosas diante desse agravo à sua subjetividade. Estudos Interdisciplinares sobre $\mathbf{0}$ Envelhecimento, v. 19, n. 3, p. 853-877, 2014.

GONZALEZ REY, F. L. Pesquisa qualitativa e subjetividade. São Paulo: Pioneira Thompson, 2005.

HELOANI, R.; LANCMAN, S. Psicodinâmica do trabalho: o método clínico de intervenção e investigação. Revista Produção, v. 14, n. 3, p. 77-86, 2004.

IBRAHIM, F. Z. Curso de direito previdenciário. 15ª ed. Rio de Janeiro: Impetus, 2010.

KARAM, H. Da alcoolização ao verbo: ensaio de Psicodinâmica do Trabalho. Brasília: Paralelo 15, 2010.

LANCMAN, S.; GHIRARDI, M. I. G. Pensando novas práticas em terapia ocupacional, saúde e trabalho. Revista de Terapia Ocupacional da Universidade de São Paulo, v. 13, n. 2, p. 44-50, 2002.

MARTINS, J. T.; BOBROFF, M. C. C.; RIBEIRO, R. P.; GASPAR, S. G.; BASANI, A. B.; STANGANELLI, N. C. Retirement: meanings for nursing professionals. Journal of Nursing UFPE on line, v. 8, n. 5, p. 1323-1329, 2014. Disponível em: < http://dx.doi.org/10.5205/reuol.5863-50531-1-ED.0805201429>. doi: 10.5205/reuol.5863-50531-1-ED.0805201429.

MENDES, A. M. Psicodinamica Do Trabalho: Teoria, Método e Pesquisas. Porto Alegre: Casa do psicólogo, 2007. 
MENDES, M. R. S. S. B.; GUSMÃO, J. L.; MANCUSSI e FARO, A. C.; LEITE, R. C. B. O. A situação social do idoso no Brasil: uma breve consideração. Acta Paulista de Enfermagem, v. 18, n. 4, p. 422-426, 2005.

SANTOS, M. de F. de S. Identidade e aposentadoria. Epu, 1990.

SOARES, D. H. P.; COSTA, A. B. Aposent-Ação: aposentadoria para ação.Vetor, 2011.

RAFALSKI, J. C.; DE ANDRADE, A. L. Planejamento da aposentadoria: Adaptação brasileira da PRePS e influência de estilos de tomada de decisão. Revista Psicologia: Organizações e Trabalho, v. 16, n. 1, p. 36-47, 2016.

RIBEIRO, G. G.; BASTOS, C. S. S. S.; DIAMANTINO, R. M.; PEDROSO, A. M. G. Perspectivas sobre a aposentadoria e o trabalho na pós-aposentadoria na terceira idade: revisão da literatura brasileira entre 1994 e 2014. UNIFACS - Seminário Estudantil de Produção Acadêmica, v. 14, n. 1, p. 144-156, 2015. 